\title{
UMA INTERPRETAÇÃO SEMIÓTICA PARA AS OBRAS $O$ ESTRANGULADOR (SHELDON, 1994) E CORRIDA PELA HERANÇA (SHELDON, 1995): O “SUSPENSE” COMO EFEITO DE SENTIDO.
}

\author{
A SEMIOTIC INTERPRETATION TO THE OPUS THE STRANGLER \\ (SHELDON, 1994) AND RUN FOR THE HERITAGE (SHELDON, 1995): THE \\ SUSPENSE AS AN EFFECT OF SENSE.
}

\author{
Bruna Longo Biasioli \\ UNESP - Universidade Estadual Paulista
}

\begin{abstract}
RESUMO: Este artigo pretende analisar duas obras de literatura infanto-juvenil que constaram nas listas dos livros mais vendidos de 1994 a 2004 (fontes: Jornal do Brasil e Jornal Leia), a saber: $O$ estrangulador (SHELDON, 1995) e Corrida pela herança (SHELDON, 1994). A semiótica greimasiana é aplicada nas análises com a função de depreender o sentido dos textos em questão, a fim de que se possa observar como se dá a composição discursiva de ambos, de modo que eles provoquem o mesmo efeito de sentido no leitor: o Suspense. Em outras palavras, será abordado, neste artigo, como se dá a formação do discurso do Suspense, à luz da teoria semiótica, tomando como exemplo os dois textos citados e recolhidos das listas dos mais vendidos.
\end{abstract}

PALAVRAS-CHAVE: Leitura; Semiótica; Suspense.

ABSTRACT: This paper proposes to analyze two opus from literature for children and teenagers that have appeared in the lists of the soldest books from 1994 to 2004, that are: The strangler (SHELDON, 1994) and Run for the heritage (SHELDON, 1995). The greimasian semiotic is applied on the analyzes with the function of stealing the sense of this texts, to observe how the discursive composition of both of them is, so as to cause the same effect of sense at the reader: the Suspense. In another words, it will be seen, in this paper, how the Suspense speach's composition is done, by the semiotic theory, taking as example the two texts named and collected from the lists of the soldest books.

KEYWORDS: Reading; Semiotic; Suspense.

Aliar teoria semiótica à questão da leitura, em relação ao que se vende mais no mercado editorial brasileiro, é um terreno muito fértil para análises. Este artigo considerou duas das obras de literatura infanto-juvenil mais vendidas no período de 1994 a 2004, $O$ estrangulador (SHELDON, 1995) e Corrida pela herança (SHELDON, 1994) ${ }^{1}$, que têm como base o Suspense enquanto efeito de sentido. À luz da teoria semiótica greimasiana, buscar-se-á, aqui, identificar a composição discursiva nesses dois textos, a fim de verificar os elementos recorrentes em ambos, que os configuram em uma mesma classificação,

\footnotetext{
${ }^{1}$ Fontes consultadas: listas semanais publicadas no Jornal do Brasil e no Jornal Leia.
} 
provocando o mesmo efeito de sentido no leitor. Essa classificação é a configuração discursiva $^{2}$ do Suspense.

O mistério e o suspense são combustíveis eficientes para as narrativas policiais. O leitor desse tipo de texto é movido pela curiosidade e estabelece, geralmente com o detetive ou policial que trabalham para desvendar o segredo, uma espécie de contrato fiduciário, em que ambos se esforçarão a fim de organizar as informações, juntar coerentemente as pistas espalhadas no decorrer do texto e, assim, acabar com o mistério.

Vale lembrar que a obra $O$ estrangulador se encaixa perfeitamente nas características que definem a narrativa policial: a constatação de um crime, a presença de pistas, a busca pelo criminoso. Já em Corrida pela herança, o que levou a caracterizá-la como narrativa policial não é a presença de um crime, mas o esquema de pistas existentes e a conseqüente busca por um saber que levará a sancionar um mistério.

De qualquer forma, encaixam-se as duas obras na configuração discursiva do Suspense, pois é esse o efeito de sentido criado no leitor. Em $O$ estrangulador, o suspense se dá até o momento em que se descobre o assassino, mas mesmo depois o efeito se mantém, pois o interesse do leitor passa a ser o de como esse assassino vai ser pego e qual o final da história e das personagens. Já em Corrida pela herança, o suspense se dá por conta de o leitor querer descobrir qual das personagens irá adquirir toda a herança do magnata e qual será a utilização do dinheiro.

A emergência da narrativa policial, segundo Dubois (1992), corresponde a uma evolução das formas literárias, mesmo que essa evolução seja escondida por fenômenos nãoliterários. Dessa forma, Dubois (1992) mostra como o romance policial deriva, em larga escala, do folhetim, que se divide em diversos grupos especializados (aventuras, antecipação, literatura para moças, etc.), os quais buscam dar conta da diversidade do público. De acordo com Almeida (s. d) ${ }^{3}$.

A imagem do universo social como labirinto é emblemática nas duas formas de romance. No folhetim, a complexidade da narrativa procura dar conta da grande cidade, labirinto ao mesmo tempo espacial e social; no RP [romance policial] clássico, a trama se assenta em geral em um grupo social restrito, quase sempre a família. Da encenação da esfera pública se passa à encenação da esfera privada. Essa passagem do público ao privado (simbolizada ainda pelo "mistério do quarto fechado") acompanha uma percepção modificada das relações de classe. Sumariamente, onde o folhetim, dentro de uma visão romântica, coloca em frente aristocracia e

\footnotetext{
${ }^{2}$ Define-se brevemente, aqui, a noção de "configuração discursiva", utilizada ao invés de "tema" e "gênero", como comumente ocorre ao se agrupar obras semelhantes quanto à estrutura e/ou ao conteúdo. Segundo Bakhtin (1997), a noção de gênero está mais ligada à questão da estrutura textual; desta noção surgem os gêneros primários (que abordam textos informais, pouco elaborados e espontâneos, como as conversas do cotidiano) e os gêneros secundários (textos mais elaborados, formais, como artigos científicos). Já a noção de tema, segundo Fiorin (1989, p. 73), remete a um "um investimento semântico de natureza conceptual”. Ele afirma, ainda, que diferentes textos podem tratar do mesmo tema, mas de maneira diferente. A configuração discursiva, segundo o autor (1989), é o efeito de sentido provocado no leitor. Assim, a configuração discursiva do suspense, por exemplo, poderia ser expressa pelo tema de um assassinato ou de um roubo. Vê-se, portanto, que a noção de configuração discursiva é mais ampla que a noção de tema. Dessa forma, classificar-se-á o Suspense, neste artigo, como uma configuração discursiva, pois trata-se da forma com que os discursos se configuram de modo a provocar o efeito de sentido do suspense no leitor.

${ }_{3}^{3}$ Resenha online de Marco Antonio de Almeida sobre o livro Le roman policier ou la modernité, de Jacques Dubois. Disponível no site: $\underline{w w w . a n p o c s . o r g . b r}$.
} 
povo, unindo-os por misteriosas passarelas, o RP colocará uma classe "média", embora a atração pela nobreza permaneça grande.

Segundo Martins (2000), há dois tipos de narrativa policial: a de sanção cognitiva (ou de detetive) e a de sanção pragmática (ou de criminoso). No primeiro caso, trata-se de uma narrativa de descoberta, tanto para o investigador do mistério, quanto para o leitor que, ao consumir essas obras, busca distração e estímulo para o raciocínio; no segundo caso, trata-se de uma narrativa de perseguição, em que, logo de início, são mostrados a identidade e os motivos do criminoso, fazendo com que o leitor desfrute do conhecimento do caso e torça para que logo o investigador possa punir o culpado. Muitas vezes, o caso é solucionado apenas para o leitor, mas não para o detetive, que tem de se esforçar muito para desvendá-lo.

Vale lembrar que uma característica das narrativas de criminoso, de sanção pragmática, que as diferem das narrativas de detetive, é que no primeiro caso, a punição recebida pelo criminoso é descrita na história, conforme será mostrado posteriormente, enquanto no segundo caso, o que interessa ao leitor é a descoberta da identidade do criminoso, não tendo muita importância se, depois do desvendar do mistério, ele será punido ou não.

Há, nas listas já aqui citadas dos livros infanto-juvenis mais vendidos entre 1994 e 2004, um exemplo de cada um desses dois tipos de narrativa policial. O primeiro deles, $O$ estrangulador, enquadra-se no segundo exemplo de narrativa policial, a narrativa de perseguição.

A história narrada é a de um assassino que matava mulheres nas ruas de Londres. O criminoso agia somente nos dias de chuva e, para desespero da polícia, não deixava rastros, e o único parâmetro para a escolha de suas vítimas era o fato de serem mulheres; a idade, a classe social, a raça não importavam.

Sem saber o que fazer, o inspetor West chamou o competente sargento Sekio Takagi a fim de que ele resolvesse o caso. A princípio, o sargento ficou sem saber por que direção começar, mas prometeu desvendar o mistério. Eis que na metade do primeiro capítulo, a identidade do assassino e os motivos que o levavam a cometer os crimes são revelados, apenas para o leitor.

O nome do assassino era Alan Simpson. Quando era criança, ele sempre ficava sozinho, pois seu pai trabalhava o dia todo em uma fábrica de sabão, e sua mãe, que deveria ficar em casa cuidando dele, nunca o esperava chegar da escola. O menino tinha adoração pela mãe e cobrava-lhe atenção; esta, por sua vez, sempre prometia que o esperaria chegar da escola, mas sempre surgia "alguma coisa importante para fazer" (SHELDON, 1995, p. 15) e o menino e o pai, se quisessem jantar, tinham que abrir alimentos enlatados para comer.

Cansado dessa situação, um dia Alan faltou à escola e seguiu a mãe. O garoto a viu entrar em um prédio, para ele desconhecido, e esperou para ver o que aconteceria. Neste instante, começou a chover. Alan viu, por meio de uma janela aberta, a mãe abraçar e beijar um homem e, tomado de um ódio muito grande, descobriu que a mãe era uma prostituta. A partir daí, passou a achar que todas as mulheres do mundo eram prostitutas.

Alan nunca deixou que sua família descobrisse que ele tinha consciência dos fatos, mas assim que pôde, saiu de casa e passou a rodar pelo mundo, tendo diversos empregos.

Movido por esse ódio, estabeleceu que seria um favor à humanidade que ele matasse todas as mulheres, e a chuva, para ele, era um aviso divino de que chegara a hora de mais uma delas ser morta. Assim, ia ao supermercado sempre que chovia, olhava as mulheres comprando alimentos para o jantar e as lembranças de sua infância o atormentavam, pois ele 
não tivera nada daquilo. Pensava consigo como seria a família daquelas mulheres e sentia pena, pois achava que elas também enganavam seus parentes.

Depois de escolhida sua vítima (havia de ser uma mulher sem proteção contra a chuva), ia para a saída do supermercado, mostrava-se muito simpático e oferecia para levála até em casa, com seu guarda-chuva. No meio do caminho, em alguma rua escura, fechava seu guarda-chuva, atingia a vítima com sua ponta, fazendo com que ela caísse, e então a estrangulava com uma corda que ficava em seu bolso. Depois de morta, Alan virava o corpo da mulher para cima, a fim de que a chuva lavasse seus pecados.

E assim fez com várias mulheres, deixando a polícia completamente perdida. Eis, porém, que uma delas seria a chave de todo o mistério. Tratava-se da jovem escultora Akiko Kanomori, que quase morreu estrangulada, se não fosse um táxi que passava pela rua onde o crime ocorria, o que assustou Alan e o fez fugir.

Quando o sargento Sekio chegou ao local e viu que a moça estava viva, concluiu que o segredo estava prestes a ser descoberto. Akiko contou a ele o que ocorreu e prometeu-lhe fazer uma escultura do rosto do assassino. Os dias se passavam, porém, e Akiko não conseguia fazer a escultura, pois era como se tivesse que enfrentar novamente a face daquele homem.

Devido à convivência, Sekio e Akiko começaram a descobrir afinidades e começaram a sair freqüentemente. Eles estavam apaixonados.

Do outro lado, Alan, que sabia que deixara uma vítima viva, pensava em como chegar até ela e concluir o crime. Passando em frente a uma galeria de artes, viu um grande cartaz, com uma foto de Akiko, divulgando uma exposição com a jovem escultora. Fingindo ser da imprensa, descobriu, com o dono da galeria, o endereço da moça que, por morar sozinha, facilitou o acesso de Alan ao seu apartamento.

O assassino foi até lá, arrombou seu apartamento e a rendeu, dizendo que iria matá-la. Neste momento, Sekio chegou, pois ele e Akiko haviam combinado de sair para jantar, mas Alan fez com que a moça abrisse somente uma pequena parte da porta e dissesse ao sargento que estava com dor de cabeça, desmarcando o jantar.

Assim, Alan levou Akiko para seu apartamento, pois não estava chovendo e ele só poderia matar na chuva. Sekio, desconfiado, começou a investigar e descobriu que um homem pegara o endereço de Akiko na galeria.

Desesperado, Sekio viu na previsão meteorológica que aquela noite iria chover. Foi então que arriscou o seguinte plano: como sabia que Alan era um assassino metódico, que só matava suas vítimas do mesmo modo (na rua, com chuva), ele colocou policiais em várias ruas escuras dos arredores e, quando começou a chover, ficaram esperando. Veio então, um homem e uma mulher, com uma sacola de compras, andando sob um guarda-chuva. Alan a derrubou e, quando ia enforcá-la, Sekio gritou para que parasse. Alan não obedeceu, o que fez com que Sekio atirasse e o matasse.

Foi o fim do sofrimento para todas as mulheres de Londres, para a polícia e para Akiko e Sekio, que começavam uma história de amor.

Já Corrida pela herança é caracterizada pelo primeiro tipo de narrativa, a narrativa de descoberta. A história narrada é a de um magnata chamado Samuel Stone, que gostava mais de sua fortuna do que de seus próprios herdeiros. Tratava-se de um homem egoísta, avaro e grosseiro.

Samuel já havia morrido quando a história começou a ser narrada. A primeira cena era a leitura do testamento; nela estavam inseridas todas as personagens: a viúva, o sobrinho, um primo chamado David (o único cujo nome era dado), o advogado do milionário, o mordomo e uma criada. A fortuna do magnata era avaliada em cem milhões de dólares. 
Nenhuma personagem, exceto David, havia lamentado a morte de Samuel, e este também não tinha nenhum apreço por seus herdeiros. Todos estavam ansiosos por saber quanto receberiam e faziam planos para gastar o dinheiro; a viúva compraria jóias, iates, roupas e um castelo na França, o sobrinho gastaria com carros modernos e mulheres, o primo David entregaria toda sua parte às instituições de caridade que ajudava, o advogado compraria um belo prédio para montar um escritório novo e impressionar seus clientes, e o mordomo e a criada mal podiam fazer planos, pois Samuel deixara somente dez mil dólares para cada.

$\mathrm{O}$ advogado tomou a palavra e informou aos outros herdeiros que Samuel não deixou um testamento convencional, mas sim várias fitas de vídeo contendo enigmas que os levariam a descobrir onde estavam investidos seus cem milhões de dólares. A cada segundafeira de manhã seria exibida uma fita. Os herdeiros ficaram revoltados e diziam que nem depois de morto Samuel conseguia deixá-los em paz.

$\mathrm{Na}$ primeira fita, o milionário disse que exigia que todos os herdeiros morassem na mesma casa, a fim de vigiar uns aos outros e disse, também, apenas uma frase que poderia servir de pista: "Cuidem bem de Oliver!" (SHELDON, 1994, p. 11). Todos estavam enfurecidos, mas David, que era o mais esperto, chegou à conclusão de que Oliver, o papagaio de Samuel, poderia entregar a primeira pista.

Todos foram falar com o papagaio que, por sua vez, recusava-se a falar de boa vontade. Eis o trecho que narra o diálogo:

O papagaio gritou estridente:

- Vá embora, talhador!

- Por que ele a chamou de talhador? - perguntou o sobrinho.

David sugeriu:

- Pode ser uma pista.

O papagaio gritou de novo:

- Pista, pista, Michael Angel!

- Isso não faz o menor sentido - murmurou o advogado.

David se tornou de repente muito excitado.

- Faz, sim! Juntem tudo. Um talhador pode ser um escultor, e Michael Angel pode ser Michelangelo.

- É isso! Samuel possuía um Michelangelo. Deve valer milhões.

- Onde está? - perguntou o sobrinho.

- Em Los Angeles. No Museu do Condado. (SHELDON, 1994, p. 13).

E assim, foram todos para o Museu, a fim de ver quem chegava antes e pegava a obra que valia milhões. A história toda se passou dessa maneira; todos corriam para decifrar as pistas deixadas por Samuel, nem que para isso precisassem trapacear os concorrentes. $\mathrm{O}$ único correto era David que, muito nobre e justo, era movido apenas pelo interesse de ajudar os necessitados, o que causava revolta nos outros companheiros, que consideravam um desperdício.

A cada semana, Samuel soltava um enigma que servia de pista para os herdeiros, que tinham que se esforçar muito para decifrar os mistérios. David era o mais inteligente e quase sempre era ele quem chegava primeiro ao destino certo, pegando o dinheiro e dando às obras de caridade. Para chegar aos pertences valiosos do magnata, as personagens tinham de fazer viagens, descobrir pessoas e enganar muitas delas.

Muitas vezes combinavam trabalhar em equipe e dividir o dinheiro, porém isso só ocorria quando era David quem desvendava o segredo; caso fosse qualquer um dos outros herdeiros, o restante do grupo seria enganado. 
Entre os pertences milionários do magnata, havia um osso de dinossauro do Museu Natural, um original de Shakespeare, artefatos indígenas raros, um selo valioso, uma patente da máquina do tempo, um colar de pedras preciosas, uma jazida de petróleo, entre vários outros.

Os herdeiros se dedicavam integralmente à descoberta de cada mistério. No final, o último objeto valioso de Samuel era a patente da máquina do tempo. Como David chegou a ela, vendeu-a para uma Universidade, que estava interessada em investir nesse tipo de pesquisa, e deu todo o dinheiro à Fundação Samuel Stone, criada por ele. E as personagens, cansadas, disseram que tinham certeza de que, com isso tudo, o velho havia se divertido do lugar onde estava.

Analisando as duas obras que este artigo propõe, pode-se dizer que suspense é um efeito de sentido criado nas narrativas policiais a partir "do arranjo narrativo/discursivo que sustenta tal tipo de texto." (MARTINS, 2000, p. 161). Em outras palavras, trata-se de um efeito criado por meio do modo pelo qual se dispõem os atores, os espaços e os tempos discursivos que revestem figurativamente os sujeitos dos esquemas narrativos que compõem a obra.

Nas obras de suspense, que contêm um crime ou não, o que leva o ator a agir é algum tipo de paixão. Esse elemento, se dotado de alta intensidade, é algo que se sobrepõe à lucidez. Assim, o ator apaixonado nunca irá agir com a razão, cometendo atrocidades, mesquinharias e coisas que ultrapassam os limites da lógica. É a paixão que transforma o sujeito do estado em sujeito do fazer.

Com o desenvolvimento dos estudos da semiótica, Greimas (1991) elaborou a teoria das paixões que, além do estado do objeto, estuda os estados da alma do sujeito narrativo. Articula, dessa forma, ação e paixão, e incorpora em seu modelo teórico, juntamente com as ações, a descrição das paixões que orientam as transformações do sujeito narrativo.

No caso de $O$ estrangulador, o que moveu Alan a matar uma série de mulheres foi o ódio, gerado por um trauma de infância. Segundo Greimas (1991), o ódio é uma paixão subseqüente ao ciúme. "O ciúme das pessoas superiores transforma-se em emulação, o dos espíritos pequenos, em ódio" (GREIMAS, 1991, p. 210). Isto é, para quem se identifica positivamente com um actante ${ }^{4}$, o ciúme será o combustível para uma rivalidade positiva, que estimulará o sujeito a entrar em conjunção com algum objeto (valor ou modal). Já para aqueles que se identificam negativamente com um actante, o ciúme causará uma repulsa, que fará com que o sujeito apaixonado queira que o outro sujeito, que está em conjunção com o objeto, entre em disjunção com ele.

De fato, Alan se deparou com a cena da mãe beijando outro homem e sentiu uma repulsa, que nutriu em seu íntimo um ódio que cresceria ao longo dos anos, fazendo com que se tornasse um assassino em série.

Em Corrida pela herança, há duas paixões que moveram dois Programas Narrativos distintos: o de Samuel Stone e o dos seus herdeiros. Samuel Stone foi um homem

${ }^{4}$ Vale destacar, no momento, a definição de actante. Trata-se de um termo originalmente criado por Lucien Tesnière, usado posteriormente pela semiótica, para designar o participante (pessoa, animal ou coisa) em um programa narrativo. Segundo Greimas, o actante é quem realiza ou o que realiza o ato, independentemente de qualquer outra determinação.

Aplicado à análise do discurso, um actante é uma ampla classe que agrupa uma só função dos diversos papéis de um mesmo papel actancial: herói, vilão, ajudante, entre outros. Greimas o concebe como o que realiza ou o que sofre o ato. Assim, os actantes são seres ou coisas que participam do processo. 
avaro durante toda sua vida. Segundo Greimas (1991, p. 150), a avareza é vista como a paixão por um objeto, e pode significar: (1) apego excessivo ao dinheiro; (2) paixão de acumular; (3) paixão de reter riquezas. Samuel possuía todas essas características, e deixava em suas fitas mensagens que, a todo momento, reiteravam a insatisfação por parte do magnata em deixar sua fortuna para aquelas pessoas por quem ele não nutria nenhum sentimento positivo. Para ele, o pior caso ainda era o de David, que "desperdiçaria" toda sua parte com obras filantrópicas.

Já os herdeiros agiam em busca da fortuna porque eram impulsionados pela inveja que sentiam de Samuel Stone. Configura-se a paixão da inveja, segundo Greimas (1991, p. 176), como "sentimento de tristeza, de irritação ou de ódio que nos anima contra quem possui um bem que não temos" ou "desejo de gozar de uma vantagem, de um prazer igual ao de outrem".

Nas narrativas de suspense, em que o mistério se baseia no desvendar de um assassinato ou de um segredo, como mostram, respectivamente, $O$ estrangulador e Corrida pela herança, há, muito freqüentemente, a oposição fundamental, que norteia todo o texto: vida versus morte.

Segundo Floch (2001, p. 14), o quadrado semiótico tem uma foria que sempre depende do contexto da narração. Assim, para o assassino Alan Simpson, a morte das mulheres era eufórica, pois, dessa forma, a humanidade ficaria livre de prostitutas, visto que, para ele, todas as mulheres eram prostitutas. A vida, conseqüentemente, era disfórica, pois se as mulheres continuassem vivas, continuariam enganando suas famílias. Dessa forma, Alan estabeleceu um contrato fiduciário com a morte, como se ela fosse a resolução dos problemas. Com as mulheres e o sargento Sekio Takagi, no entanto, ocorre o contrário; a vida é eufórica e a morte disfórica, como são dentro de um padrão normal.

Para o milionário Samuel Stone, a vida era eufórica, pois representava a possibilidade de ficar com toda sua fortuna e não deixá-la a ninguém. Assim, a morte era disfórica, visto que, depois de morto, teria que deixar seus cem milhões de dólares aos seus herdeiros indesejáveis. Para eles, no entanto, a vida de Samuel Stone era disfórica, o que significava estar em disjunção com o objeto-valor a que tanto almejavam (a fortuna do magnata), enquanto sua morte era eufórica, pois permitiria a conjunção com o dinheiro.

A oposição vida versus morte, no entanto, está em todo discurso, pois tudo gira em torno dessas duas noções. Assim, em $O$ estrangulador e Corrida pela herança, o que se pode dizer é que as oposições de base que norteiam o texto é o segredo versus seu desvelamento. No primeiro caso, o segredo, para as personagens é a identidade do assassino; no segundo, é onde está investida a fortuna do magnata. O trabalho das personagens, dessa forma, está em desvelar os segredos que mantêm o suspense nas obras, transformando um estado inicial de não saber a um estado final de saber.

De acordo com Barros (1988, p. 46), o que produz os efeitos de sentido afetivos ou passionais é a modalização do ser, ou seja, as características que atribuem existência modal ao sujeito de estado.

Dois ângulos devem ser examinados, na modalização do ser: o da modalização veridictória, que determina a relação do sujeito com o objeto, dizendo-a verdadeira [ser e parecer] ou falsa [não-parecer e não-ser], mentirosa [parecer e não-ser] ou secreta [ser e não-parecer], e o da modalização pelo querer, dever, poder e saber, que incide especificamente sobre os valores investidos nos objetos. 
Analisando, em $O$ estrangulador, os dois atores principais - o assassino e o sargento -, pode-se dizer que Alan Simpson realiza o percurso da mentira ${ }^{5}$, pois ele parece ser bom, oferecendo gentilmente seu guarda-chuva às mulheres, mas não é, e Sekio Takagi realiza o percurso da verdade, pois ele parece ser bom e realmente é. Vale lembrar que o que está em questão é o valor da bondade (que inclui honestidade, bom senso, entre outros); caso fosse o valor da maldade, Alan estaria no nível do segredo, pois não parece ser mau, mas é.

Em Corrida pela herança, o magnata Samuel Stone desempenha o percurso da falsidade, pois ele não parece e não é uma pessoa boa; seus herdeiros, no entanto, exceto David, desempenham percurso da mentira, uma vez que eles demonstram, uns para os outros, serem pessoas boas, dispostas a ajudarem-se mutuamente na busca pela herança, porém, não o são, já que almejavam sempre achar o dinheiro e não repartir com os demais. David realiza o percurso da verdade, pois ele parece e realmente é uma pessoa boa.

Observa-se, assim, que as narrativas de suspense, por mais que contenham outros níveis de modalização do sujeito, têm como base a verdade e a mentira. A verdade modaliza o detetive, o investigador ou quem estiver querendo desvendar o mistério, e nas duas obras analisadas cabe ao sargento Sekio e a David, o único herdeiro honesto; e a mentira, geralmente, modaliza o criminoso ou o desonesto, características que revestem Alan e os herdeiros de Samuel, à exceção de David. O segredo também é uma modalidade bastante pertinente às obras de suspense, visto que a narrativa gira em torno de seu desvendar.

Há em $O$ estrangulador um programa narrativo $(\mathrm{PN})$ de base, realizado pelo ator Sekio que quer entrar em conjunção com um saber, que é a descoberta do criminoso. $\mathrm{O}$ outro PN, que provocou o surgimento do PN de base, é o de Alan, que queria provocar a morte em quantas mulheres ele conseguisse; há, ainda, o PN de Sekio e Akiko, que começaram a viver uma história de amor.

Como citado por Barros (1988, p. 46), os atores também são modalizados pelo querer, dever, poder e saber. Em $O$ estrangulador, Alan era manipulado por um trauma da infância, e possuía as quatro modalidades que, juntas, davam-lhe competência para o desenrolar da performance na narrativa. Em outras palavras, Alan queria matar, pois, para ele, o fim das mulheres seria bom para a humanidade; devia matar, pois em sua mente isso era uma obrigação que se fazia necessária à vingança; podia matar, pois tinha a corda para os estrangulamentos e um plano para realizá-los; e, por fim, sabia matar, visto que tinha conhecimento de como estrangular suas vítimas. Assim, todos os estrangulamentos foram realizados, exceto o de Akiko, que foi interrompido pela presença de um taxista, o que quebrou uma das competências do assassino (a do poder matar, pois seu plano já não poderia mais ser efetivado).

O percurso narrativo do destinador-manipulador é cumprido pela mãe, pois é ela a destinadora do valor modal (o dever matar, gerado pelo ódio, que impulsionou suas ações), doando-o ao sujeito de estado, Alan. Já o percurso narrativo do destinador-julgador é executado pelo sargento Sekio, em virtude dele responder pela sanção do sujeito; o destinador julga o sujeito pela verificação de suas ações e dos valores com os quais se relaciona.

Em Corrida pela herança, o grande manipulador de Samuel Stone era o dinheiro, que fazia com que o milionário agisse da forma mesquinha com que tratava seus herdeiros, ao mesmo tempo em que dificultava, por apego, o acesso das outras personagens à fortuna. Assim, Samuel, ainda quando vivo, arrumou um meio para que, mesmo depois de morto, pudesse atrapalhar os herdeiros, pois gostava muito mais de sua fortuna do que deles próprios. Ele, portanto, queria atrapalhá-los; devia atrapalhá-los, pois, em sua mente, os

\footnotetext{
${ }^{5}$ As definições das modalidades segredo, mentira, verdade e falsidade se encontram em Greimas \& Courtès, s. d, p. 488.
} 
herdeiros não mereciam desfrutar facilmente de toda a herança; podia atrapalhá-los, já que tinha como aliado algo que deslumbrava os demais (muito dinheiro); e, finalmente, sabia atrapalhá-los, pois seus enigmas os deixavam sempre muito confusos, o que atrasava o acesso à herança.

A manipulação foi feita por meio da tentação, já que os herdeiros receberiam algo (dinheiro) em troca de uma ou mais ações (o desvendamento dos enigmas e a chegada até os objetos que constituíam a fortuna de Samuel). Assim, o percurso do destinadormanipulador é realizado por Samuel, pois foi ele quem instaurou, nos outros atores, os valores modais (querer fazer, no caso, querer realizar a ação de buscar a herança) necessários à performance dos herdeiros. Estes, por sua vez, desenvolvem o percurso narrativo do destinador-julgador, pois foram eles que julgaram o sistema de valores (ambição, riqueza) que Samuel representava.

O PN de base em Corrida pela herança é, assim, a busca dos herdeiros que querem entrar em conjunção com a fortuna do magnata, como o próprio título da história sugere. Os PNs descritos pelas aventuras dos herdeiros em busca da herança são subprogramas do PN principal, que podem ser caracterizados, por exemplo, pelas histórias ocorridas no museu, na Espanha, no circo que se instalara na cidade, entre outros locais que faziam parte das pistas oferecidas por Samuel, e que poderiam conter alguma preciosidade do magnata, tão cobiçada pelas outras personagens.

Todos os actantes e todas as transformações já descritas são revestidas por figuras. Assim, em $O$ estrangulador, o tema do assassinato (actante) é revestido pelo estrangulamento (figura). Em outras palavras, para Alan fazer com que as mulheres entrassem em conjunção com a morte, ou seja, para provocar o assassinato, valeu-se do estrangulamento. Em Corrida pela herança, o tema da riqueza (actante) é representado pelas obras valiosas de Samuel, como o colar precioso, o original de Shakespeare, a jazida de petróleo, etc. (figuras). Isto é, para os herdeiros entrarem em conjunção com a riqueza, eles precisavam se apoderar das figuras que revestiam esse valor, que são os bens de Samuel. Como afirma Bertrand (2003, p. 84):

Por meio da operação de "discursivização", ela organiza a passagem das estruturas elementares e semionarrativas virtuais, consideradas aquém da enunciação, como um estoque de formas disponíveis (uma gramática), para as estruturas discursivas (temáticas e figurativas), que as atualizam e especificam, em cada ocorrência, no interior do discurso que se realiza.

Para constituir o discurso, a enunciação se utiliza das categorias de pessoa, de tempo e de espaço. Em $O$ estrangulador, o sujeito do discurso é dotado de um "eu- aquiagora", representado, na verdade, por um "ele (Alan, Sekio, Akiko)- lá (Londres)- então (passado indeterminado)". A enunciação da narrativa é modalizada por meio do mecanismo da debreagem enunciva, da qual resulta o efeito de sentido da objetividade. Pela debreagem enunciva, o narrador se distancia do discurso, contando a história através da 3a pessoa: "Um estrangulador estava à solta nas ruas de Londres. Até agora, já matara seis mulheres (...)”. (SHELDON, 1995, p. 7).

A fim de proporcionar ao enunciatário a ilusão de ouvir as personagens, ou seja, a fim de dar à narrativa o efeito de realidade, o enunciador de $O$ estrangulador, muitas vezes, dá voz às personagens. Por meio da debreagem interna (ou de 20 grau), o enunciador cria a unidade discursiva denominada discurso direto: "Enquanto andavam pela rua, sob o 
aguaceiro, o estrangulador comentou: - É uma coisa inevitável em Londres. Se você não gosta do tempo, espere só um pouco, que logo muda." (SHELDON, 1995, p. 61).

O discurso direto, aparentemente desnecessário, visto que o narrador já está com a palavra, é utilizado para "distinguir bem as opiniões exteriorizadas das mantidas no seu [do narrador] íntimo." (FIORIN, 1989, p. 51).

Em Corrida pela herança, os mecanismos são os mesmos, o que, conseqüentemente, rendem à narrativa o mesmo efeito de objetividade expresso em $O$ estrangulador. A enunciação também é modalizada por um "ele (Samuel ou os herdeiros)- lá (casa de Samuel e locais onde estavam os seus bens)- então (passado indeterminado)". Por meio da debreagem enunciva, o narrador fica distante dos fatos narrados: "Esta é a história de um homem chamado Samuel Stone, tão rico e poderoso que se recusa a morrer." (SHELDON, 1994, p. 7).

Assim como em $O$ estrangulador, o narrador se utiliza, por meio da debreagem interna (ou de segundo grau), dos discursos diretos, a fim de passar a palavra às personagens e render à obra o efeito de realidade: “(...) O diretor chamou todos à sua sala e disse: - Não sei o que deu em vocês, mas há algo muito estranho em tudo isso. Pelo que sei, todos estão ligados a Samuel Stone." (SHELDON, 1994, p. 101).

Percebe-se que, em ambas as obras, há uma mescla de vozes, a do narrador e a das personagens. A narrativa é marcada pela presença de ambos os discursos: direto e indireto. No discurso direto, como já visto, o narrador limita-se a introduzir a fala da personagem, deixando-a exprimir-se por si mesma, com suas próprias palavras.

No discurso indireto, o narrador incorpora à sua fala o discurso da personagem, introduzindo-o indiretamente através de um verbo de elocução (dizer, afirmar, confessar, perguntar, responder, etc.) e de uma oração subordinada substantiva, introduzida geralmente pela conjunção que, como no exemplo: "No testamento, anunciou que a viúva, o sobrinho e o advogado viveriam juntos em sua casa, enquanto tentavam descobrir o tesouro." (SHELDON, 1994, p. 49).

Assim, no discurso indireto, a fala da personagem adquire um tom mais informativo, devido ao fato de vir introduzida por meio da subordinação sintático-semântica, que busca estabelecer uma correspondência entre a fala realmente pronunciada pela personagem e a frase reproduzida pelo narrador.

Desta forma, conclui-se que há várias semelhanças entre os dois discursos, mesmo sendo histórias diferentes. Isso prova que a partir do momento em que duas ou mais histórias se configuram discursivamente de modo semelhante, é porque o efeito de sentido provocado por elas será o mesmo. Neste caso, o Suspense sustentou o desenrolar das duas narrativas. Para isso, foram necessários recursos de enunciação e de modalização, ou seja, o discurso se configurou de maneira específica para que o efeito de sentido do Suspense se mantivesse.

Por fim, vale destacar que a modalidade do "segredo" é bastante pertinente nas narrativas policiais e pode-se dizer que o segredo consiste em uma das formas de se manter o efeito de sentido do Suspense que há nas duas obras analisadas. Na primeira, $O$ estrangulador, o segredo não é mantido para o leitor, pois a identidade e os motivos do assassino já foram ditos no início do texto, mas esta modalidade se mantém para as personagens da história, o que faz com que o leitor queira acompanhar o desvendar de todo mistério a fim de saber como será o desfecho de tudo e de todos.

Além disso, o Suspense se dá em cada momento em que o leitor não sabe o que, ao certo, vai ocorrer, o que o leva a questionar: Akiko conseguirá despistar o estrangulador? Alan conseguirá enforcar a moça ou surgirá alguém para ajudar? Será que o 
plano de Sekio para capturar o estrangulador dará certo logo de início? E, como uma característica comum às narrativas policiais: Sekio e Akiko viverão um grande amor?

$\mathrm{Na}$ segunda narrativa, em que o segredo são os locais onde estão investidos os milhões do magnata Samuel Stone, o Suspense se dá pelas pistas enviadas pelo milionário, que são um segredo até para o leitor, que tenta decifrá-las juntamente com as personagens.

Assim, percebe-se que a modalidade do segredo é o que mantém o Suspense nas obras analisadas e, para isso, seus discursos devem se configurar de formas semelhantes, a fim de que o efeito desejado seja realmente provocado no leitor.

\section{Referências Bibliográficas:}

ALMEIDA, Marco Antonio de. Resenha de Le roman policier ou la modernité ( texto de Jacques Dubois). Disponível na internet via www.anpocs.org.br. Acesso em 20/06/09, 14 h 32.

BARROS, Diana Luz Pessoa de. Teoria do discurso: Fundamentos semióticos. São Paulo: Atual, 1988.

BAKHTIN, M. Os gêneros do discurso. In: Estética da Criação Verbal. 2a. ed. São Paulo : Martins Fontes, 1997.

BERTRAND, Denis. Caminhos da semiótica literária. (trad. Grupo CASA). Bauru: Edusc, 2003.

DUBOIS, Jacques. Le roman policier ou la modernité. Paris : Éditions Nathan, 1992.

FIORIN, José Luiz de. Elementos de análise do discurso. São Paulo: Contexto/EDUSP, 1989. (Repensando a Língua Portuguesa).

FLOCH, Jean-Marie. Alguns conceitos fundamentais em Semiótica geral. Documentos de estudo do Centro de Pesquisas Sociossemióticas. São Paulo: Edições CPS, 2001.

GREIMAS, Algirdas Julien \& FONTANILLE, Jacques. Semiótica das paixões. Dos estados das coisas aos estados de alma. Trad. De Maria José Rodrigues Coracini. São Paulo: Ática, 1991.

MARTINS, Marcelo Machado. Narrativa policial: uma abordagem semiótica. Dissertação de mestrado apresentada ao Programa de Lingüística da Faculdade de Filosofia, Ciências, Letras e Ciências Humanas da USP. São Paulo, 2000.

SHELDON, Sidney. O estrangulador. São Paulo: Record, 1995.

Corrida pela herança. São Paulo: Record, 1995. 